\title{
Geriatric assessment in daily oncology practice for nurses and allied health care professionals: Opinion paper of the Nursing and Allied Health Interest Group of the International Society of Geriatric Oncology (SIOG)
}

\author{
Peggy S. Burhenn ${ }^{a, *}$, Alexandra L. McCarthy ${ }^{b, c}$, Aaron Begue ${ }^{d}$, Ginah Nightingale, \\ Karis Cheng ${ }^{f}$, Cindy Kenis ${ }^{g}$ \\ ${ }^{a}$ Department of Professional Practice and Education, City of Hope, Duarte, United States \\ ${ }^{b}$ Division of Cancer Services, Princess Alexandra Hospital, Brisbane, Australia \\ ${ }^{\mathrm{C}}$ Queensland University of Technology, Brisbane, Australia \\ ${ }^{\mathrm{d} D e p a r t m e n t ~ o f ~ H e a l t h ~ S y s t e m ~ A d m i n i s t r a t i o n, ~ T h e ~ O h i o ~ S t a t e ~ U n i v e r s i t y ~ H e a l t h ~ S y s t e m, ~ C o l u m b u s, ~ U n i t e d ~ S t a t e s ~}$ \\ e Department of Pharmacy Practice, Jefferson School of Pharmacy, Philadelphia, United States \\ ${ }^{\mathrm{f}}$ Alice Lee Centre for Nursing Studies, National University of Singapore, Singapore, Singapore \\ gDepartment of General Medical Oncology And Geriatric Medicine, University Hospitals Leuven, Leuven, Belgium
}

\section{A R T I C L E I N F O}

Article history:

Received 5 August 2015

Received in revised form

19 January 2016

Accepted 10 February 2016

Keywords:

Geriatric assessment

Older persons

Nursing

Oncology

Geriatric oncology nursing

Allied health

\begin{abstract}
A B S T R A C T
The management of older persons with cancer has become a major public health concern in developed countries because of the aging of the population and the steady increase in cancer incidence with advancing age. Nurses and allied health care professionals are challenged to address the needs of this growing population. The International Society of Geriatric Oncology (SIOG) Nursing and Allied Health (NAH) Interest Group described key issues that nurses and allied health care professionals face when caring for older persons with cancer. The domains of the Geriatric Assessment (GA) are used as a guiding framework. The following geriatric domains are described: demographic data and social support, functional status, cognition, mental health, nutritional status, fatigue, comorbidities, polypharmacy, and other geriatric syndromes (e.g. falls, delirium). In addition to these geriatric domains, quality of life (QoL) is described based on the overall importance in this particular population. Advice for integration of assessment of these geriatric domains into daily oncology practice is made. Research has mainly focused on the role of treating physicians but the involvement of nurses and allied health care professionals is crucial in the care of older persons with cancer through the GA process. The ability of nurses and allied health care professionals to perform this assessment requires specialized training and education beyond standard oncology knowledge.
\end{abstract}

(c) 2016 Elsevier Ltd. All rights reserved.

\footnotetext{
* Corresponding author at: 1500 Duarte Road, Duarte, CA 91010, United States. Tel.: +1 626359 8111; fax: +1 6263018126.

E-mail address: pburhenn@coh.org (P.S. Burhenn).
} 


\section{Contents}

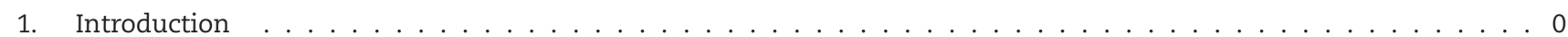

2. Sociodemographics, Social Support, and the Older Adult with Cancer . . . . . . . . . . . . . . . . . . . . . . . 0

2.1. Advice for Nurses and Allied Health Care Professionals . . . . . . . . . . . . . . . . . . . . . . . . . . 0

3. Comorbidities and the Older Adult with Cancer . . . . . . . . . . . . . . . . . . . . . . . . . 0

3.1. Advice for Nurses and Allied Health Care Professionals . . . . . . . . . . . . . . . . . . . . . . . . . . 0

4. Functional Status and the Older Adult with Cancer . . . . . . . . . . . . . . . . . . . . . . . . . . . 0

4.1. Advice for Nurses and Allied Health Care Professionals . . . . . . . . . . . . . . . . . . . . . . . . . . 0

5. Cognition and the Older Adult with Cancer . . . . . . . . . . . . . . . . . . . . . . . . . . . 0

5.1. Advice for Nurses and Allied Health Care Professionals . . . . . . . . . . . . . . . . . . . . . . . . . . 0

6. Depression and the Older Adult with Cancer . . . . . . . . . . . . . . . . . . . . . . . . . . . . 0

6.1. Advice for Nurses and Allied Health Care Professionals . . . . . . . . . . . . . . . . . . . . . . . . 0

7. Nutrition and the Older Adult with Cancer . . . . . . . . . . . . . . . . . . . . . . . . . . . 0

7.1. Advice for Nurses and Allied Health Care Professionals . . . . . . . . . . . . . . . . . . . . . . . . . . 0

8. Fatigue and the Older Adult with Cancer . . . . . . . . . . . . . . . . . . . . . . . . . . 0

8.1. Advice for Nurses and Allied Health Care Professionals . . . . . . . . . . . . . . . . . . . . . . . . . . 0

9. Polypharmacy and Medication Related Problems in the Older Adult with Cancer . . . . . . . . . . . . . . . . . . . . 0

9.1. Advice for Nurses and Allied Health Care Professionals . . . . . . . . . . . . . . . . . . . . . . . . . . 0

10. Geriatric Syndromes in General and the Older Adult with Cancer . . . . . . . . . . . . . . . . . . . . . . . 0

10.1. Advice for Nurses and Allied Health Care Professionals . . . . . . . . . . . . . . . . . . . . . . . . . . 0

11. Geriatric Syndrome: Delirium and the Older Adult with Cancer . . . . . . . . . . . . . . . . . . . . . . . . . 0

11.1. Advice for Nurses and Allied Health Care Professionals . . . . . . . . . . . . . . . . . . . . . . . . 0

12. Geriatric Syndrome: Falls and the Older Adult with Cancer . . . . . . . . . . . . . . . . . . . . . . . . . 0

12.1. Advice for Nurses and Allied Health Care Professionals . . . . . . . . . . . . . . . . . . . . . 0

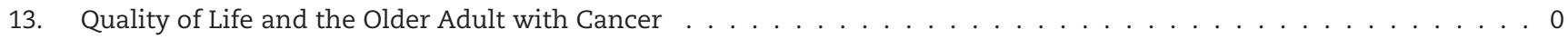

13.1. Advice for Nurses and Allied Health Care Professionals . . . . . . . . . . . . . . . . . . . . . . . 0

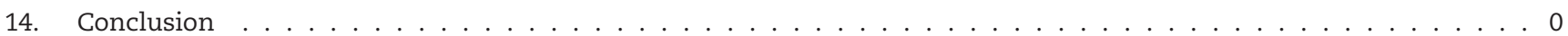

Disclosures and Conflict of Interest Statement . . . . . . . . . . . . . . . . . . . . . . . . . . 0

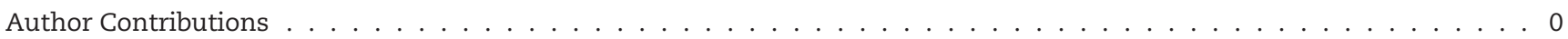

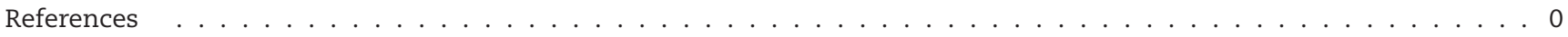

\section{Introduction}

Worldwide cancer occurs more commonly in older persons. ${ }^{1}$ The Institute of Medicine (IOM) noted a gap in the educational preparation of health care professionals to care for this aging population and called on the health care community to develop innovative ways to improve care for older patients. ${ }^{2}$ Nurses and allied health care professionals play a key role in caring for older patients with cancer both hospitalized and ambulatory patients, since the latter is of increasing importance in daily oncology practice. Globally they can develop an awareness of the special needs of older patients, gain education in the science of geriatrics, and provide age-sensitive care to optimize care of the older patient with cancer.

The International Society of Geriatric Oncology (SIOG) Nursing and Allied Health (NAH) Interest Group identified a need to share state of the art knowledge with other nurses and allied health care professionals about the special needs of caring for older patients with cancer. To describe these special needs, Comprehensive Geriatric Assessment (CGA) is recommended. CGA is defined as a 'multidimensional, interdisciplinary diagnostic process focusing on determining an older person's medical, psychosocial and functional capability in order to develop a coordinated and integrated plan for treatment and long-term follow-up'. ${ }^{3}$ In summary, this method comprises five consecutive steps and is the main principle of modern geriatric medicine ${ }^{4}$ : identifying patients who can benefit from CGA; assessing these patients; developing recommendations for geriatric interventions based on the detected problems by CGA; implementing these recommendations in a care plan; and provision of follow-up and adjustment of the care plan with repeated CGA. Because CGA research specifically in oncology has mainly studied the steps of geriatric screening and assessment, the term geriatric assessment (GA) is recommended rather than CGA. $^{5}$

In the past decade guidelines for Geriatric Assessment (GA) have been developed under auspices of SIOG. ${ }^{5,6}$ The current guideline defines the geriatric domains to consider when caring for older adults with cancer: demographic data and social support, functional status, cognition, mental health, nutritional status, fatigue, comorbidities, polypharmacy, and other geriatric syndromes (e.g. delirium, falls). ${ }^{5}$ In addition to these geriatric domains, quality of life (QoL) is described due to its significance to nursing and patient outcomes. ${ }^{7}$

The aim of this opinion paper is to outline the key domains of the GA and QoL for nurses and allied health care professionals when caring for older patients with cancer and to address practical advice. 


\section{Sociodemographics, Social Support, and the Older Adult with Cancer}

It is widely understood that older persons all over the world are among the most sociodemographically challenged in terms of income, health literacy, and access to health care. ${ }^{8}$ Social isolation and disadvantage are considered independent predictors of mortality in the older population with cancer because adequate social support provides a buffer against the stress inherent in the illness. ${ }^{9}$ It is therefore important to assess the psychosocial variables that might usefully inform treatment decision-making, such as the presence and adequacy of a caregiver, living conditions, level of income, and access to transportation. ${ }^{10}$

\subsection{Advice for Nurses and Allied Health Care Professionals}

Demographics and social support data can be derived from self-report of the older patient or can be collected from the patient chart. The choice of instrument to assess the patient's level of social support will depend on the precise context of practice and the human and material resources available. There are not many instruments available for this purpose but one of the more commonly used is the Medical Outcomes Social Support Survey (MOS-SS) which is used in the geriatric oncology setting. ${ }^{11}$ Any concerns identified by the information reported by the older patient or by the instrument can trigger a referral to the social worker or relevant community support service.

\section{Comorbidities and the Older Adult with Cancer}

As the population ages, the prevalence of patients with cancer and comorbidities will increase. ${ }^{12}$ On average, older adults suffer from three comorbidities and those with cancer are likely to suffer from more. Registry studies report that $40 \%$ or more of older patients with cancer suffer from four or more comorbidities. ${ }^{13}$ Not only cancer survival but also cancer treatment is impacted by comorbidities. Older patients with cancer and comorbidities are less likely to receive cancer treatment, less likely to tolerate side effects, and are less likely to complete therapy. ${ }^{12}$

\subsection{Advice for Nurses and Allied Health Care Professionals}

A comprehensive health history to assess comorbidities is vital to the care of the older patient with cancer and is evaluated before, during and after cancer treatment. The comorbidities of the patient can be obtained during the initial visit when the history and physical are conducted. ${ }^{13}$ They are also collected as part of the GA, however, the health care team member that collects this information may vary by country. The use of validated comorbidity scales, such as the Charlson Comorbidity Index $(\mathrm{CCI})^{14}$ or the Cumulative Illness Rating Scale for Geriatrics (CIRS-G) ${ }^{15}$ can be incorporated into the GA. These scales can be useful in predicting outcomes in older patients with cancer. ${ }^{16}$ It is advisable that comorbidities also are examined individually as certain conditions may have a greater impact on cancer treatment outcomes than others. ${ }^{17}$ Collaboration with the patient's primary care provider and sharing the plan of care and treatment summary is a best practice to integrate the management of cancer care and comorbidities.

\section{Functional Status and the Older Adult with Cancer}

Maintenance of functional status is a key issue for older persons, certainly for those diagnosed with cancer. Functional impairment has been independently associated with increased comorbidities ${ }^{18}$ and shorter survival ${ }^{19}$ and can lead to higher dependency, institutionalization, and decreased QoL. ${ }^{19,20}$ Repeated assessment of functional status over time gives health care professionals in general the opportunity to identify functional decline, which is a major threat for older persons in general ${ }^{21}$ with increased risk for hospital and nursing home admission and mortality. ${ }^{22-24}$ The possibility to predict functional decline is crucial as it could allow preventive measures for patients at risk. , 25,26 $^{2}$

\subsection{Advice for Nurses and Allied Health Care Professionals}

Tools such as Karnofsky ${ }^{27}$ or Eastern Cooperative Oncology group Performance Status (ECOG-PS) ${ }^{28}$ scales reflect functional status in a very simplistic way, and were not specifically developed and validated in the older population. More sophisticated and age-adapted tools used in geriatric medicine are Katz's Activities of Daily Living (ADL) $\mathrm{scale}^{29}$ and Lawton's Instrumental Activities of Daily Living (IADL) scale. ${ }^{30}$ Both tools are commonly used in the older population with cancer. ${ }^{5,31}$ In case of functional impairments, targeted interventions (e.g. structured exercise, mobilization training, progressive resistance strength training, rehabilitation therapy) should be established in collaboration with occupational therapists or physical therapists. Follow-up needs are integrated within the care plan of the older patient to prevent functional decline.

\section{Cognition and the Older Adult with Cancer}

Older persons may experience cognitive declines as they age ranging from mild cognitive impairment (MCI) to dementia. ${ }^{32}$ Cognitive changes can impact QoL and result in functional decline. ${ }^{33,34}$ Prior to cancer treatment, cognitive evaluation can be performed. Depression and cognitive impairment are known as risk factors for developing delirium. ${ }^{35}$ Therefore it is important to monitor for cognitive changes in the older population with cancer to determine risk for other syndromes.

\subsection{Advice for Nurses and Allied Health Care Professionals}

Cognitive impairment can be assessed using a variety of validated tools. A simple measure of cognition can be performed using the Mini-COG ${ }^{34,36}$ or other tools mentioned in the SIOG guideline for GA. ${ }^{5}$ A patient who has cognitive impairment is assessed for decision making capacity by the treating physician to ensure understanding of care options, the rationale for the 
recommended options, the reasoning for their choice, and the ability to communicate their choice. ${ }^{34,38}$ The results of cognition screening and any identified abnormalities should be considered when recommending treatment options. For example, a patient with MCI who is responsible for independent medication management would need support going home with an oral anticancer agent. Patients with positive screens for cognitive problems should be referred to a neurologist, psychiatrist, or geriatrician as appropriate. ${ }^{38}$

\section{Depression and the Older Adult with Cancer}

Depression, ranging from the distressed mood that is a natural reaction to a distressing diagnosis to entrenched endogenous depression is common in the general older population (3-30\%). ${ }^{39}$ It has been documented in up to $22 \%$ of patients with cancer. ${ }^{40}$ While it can be as common in older patients with cancer as it is in younger individuals, and as likely to lead to adverse treatment outcomes, ${ }^{40}$ depression in older persons requires a geriatric specific assessment. Aspects of depression that warrant assessment include cognitive symptoms, memory, optimism, selfimage, loss, anxiety, obsessive traits and mood swings. ${ }^{41}$

\subsection{Advice for Nurses and Allied Health Care Professionals}

While no instrument is considered completely reliable and valid to evaluate depression in the older patient with cancer, the Geriatric Depression Scale (GDS), ${ }^{42}$ or similar provides a useful screen for risk of depression. This can then be followed up with a referral for a comprehensive psychological assessment, a referral to the psychosocial oncology program which is existing in most cancer centers, or even a referral to a support group or social worker where appropriate.

\section{Nutrition and the Older Adult with Cancer}

Malnutrition in older patients with cancer is considered a prognostic indicator of morbidity and mortality ${ }^{43}$ and is very common in the older population with cancer. In particular, unintentional weight loss in the 6 months prior to chemotherapy is associated with poorer survival and lower chemotherapy response rates ${ }^{10}$; while low body mass index (BMI) is associated with increased dependence in ADL and decreased 1-year survival. ${ }^{9}$ Body mass index (BMI) is a frequently-used measure of nutritional status and is routinely calculated in cancer settings to determine chemotherapy dose. However, $\mathrm{BMI}$ is probably not the most accurate indicator of nutritional status and potential outcomes in this context. Loss of height due to aging is often unaccounted for in these calculations and as such, BMI is often overestimated. ${ }^{44}$ Also, BMI does not distinguish lean body mass from fat mass or skeletal muscle mass, which are more reliable indicators of nutritional risk. ${ }^{45}$

\subsection{Advice for Nurses and Allied Health Care Professionals}

BMI in isolation should be used cautiously to judge nutritional status and treatment outcomes in older persons. Where BMI is the only indicator available, the age-adjusted recommended cut-offs should be taken into account for defining malnutrition or a risk for malnutrition. ${ }^{46}$ Malnutrition screening tools, such as the Malnutrition Screening Tool for Cancer Patients (MSTC) ${ }^{47}$ and Mini Nutritional Assessment (MNA), ${ }^{48}$ detect those at risk irrespective of BMI. It is advisable as a useful screen for malnutrition, which triggers a subsequent dietitian referral and more comprehensive dietetic assessment. In addition, unintentional weight loss, which is often incorporated in malnutrition screening tools, can be questioned as an easy stand-alone nutritional parameter. More specific, biochemical assessment of serum albumin, ${ }^{49}$ vitamin $\mathrm{D}^{50}$ and $\mathrm{B} 12^{51}$ levels is recommended for their relevance in the older population (e.g. related to falls, memory problems). Nurses and allied health care professionals can pay additional attention to protein and calorie intake of the older patient with cancer.

\section{Fatigue and the Older Adult with Cancer}

Cancer-related fatigue (CRF) is a common debilitating symptom, with a prevalence that reaches $70 \%$ in older patients with cancer throughout the course of disease and treatment. ${ }^{52}$ Clinically, CRF is characterized as an unusual sense of tiredness that does not relieve with adequate rest, and is disproportionate to the level of physical exertion and with concomitant daytime dysfunction. ${ }^{53}$ Although the underling mechanisms of CRF is not fully understood, it has been suggested to be related to complex neuroendocrine and biobehavioral mechanisms, and an interaction of metabolic, somatic, emotional, cognitive, and psychosocial factors associated with cancer and its treatment. ${ }^{54,55}$ Accumulating evidence has shown that CRF often co-occurs with pain, mood, and sleep disturbance, and is associated with cognitive impairment. These symptoms may have similar patterns over time, and can have synergistic effects on multiple dimensions of the QoL of older patients with cancer. ${ }^{56-58}$

\subsection{Advice for Nurses and Allied Health Care Professionals}

It is important for nurses and allied health care professionals to understand CRF and its mechanisms and full impact in the context of symptom cluster and aging. Continuous and comprehensive assessment of CRF and other contributing factors, as well as provision of strategies and resources useful in coping with CRF, is equally important. A number of instruments have been developed to measure CRF, including the Functional Assessment of Cancer Therapy: Fatigue (FACT-F) scale, ${ }^{59}$ the EORTC QLQ C30 Fatigue subscale, ${ }^{60}$ or a simple Visual Analogue Scale (VAS), ${ }^{61}$ and they are the most commonly used instruments across different cancer settings. Increasing evidence suggests that energy conservation, distraction techniques, exercise/physical activity, and cognitive behavioral therapies initiated by nurses and allied health care professionals could be effective in reducing CRF. ${ }^{62,63}$ Energy conservation may include prioritization of daily activities to prevent energy depletion, and distraction techniques may include reading and socializing to help take mind off from fatigue. Exercise/physical activity and cognitive behavioral therapies may include moderate exercise program to improve functional capacity and psychosocial program to manage 
stress. ${ }^{61-63}$ Special considerations based on age, comorbid and nutritional statuses, and frailty should be made in older population with cancer.

\section{Polypharmacy and Medication Related Problems in the Older Adult with Cancer}

A comprehensive medication assessment (e.g. prescription, non-prescription and complementary and alternative medicines and supplements) is an integral part of the geriatric oncology assessment. The National Comprehensive Cancer Network (NCCN) Older Adult Oncology Guidelines recommend a thorough evaluation for polypharmacy, potentially inappropriate medications (PIM) with subsequent discontinuation of any nonessential or high-risk medications. ${ }^{38}$ Cancer-related therapy adds to the prevalence of multiple medication use and/or inappropriate medication consumption because new medications escalate pill burden and medication regimen complexity. As a consequence, there is an increased risk for adverse drug effects, drug-drug interactions, and increased risk for non-adherence. Polypharmacy is commonly defined as concurrent use of five or more medications, including prescription, non-prescription and complementary / herbal supplements ${ }^{64-66}$ or by the prescribing of PIM which may increase the risk for adverse drug effects in older adults. Potentially inappropriate medications may be categorized based on screening tools such as the updated Beers criteria, the Screening Tool of Older Person's Prescriptions (STOPP) criteria and the Medication Appropriateness Index (MAI). ${ }^{67-74}$ Existing studies that report on the prevalence of polypharmacy and PIM use, specifically in ambulatory older adults with cancer, report the prevalence of polypharmacy as high as $84 \%$ and PIM use as high as $51 \%{ }^{75-79}$ The consequences of polypharmacy and PIM warrant substantial interest and concern because of the perils associated with their use in this vulnerable population; vulnerabilities include increased risk of falls and/or fractures, cognitive impairment, and delirium, all of which can lead to compromised cancer management plans.

\subsection{Advice for Nurses and Allied Health Care Professionals}

Medication reconciliation and rational discontinuation of non-essential and high-risk medications are critical components of medication management. The brown bag method is recommended and involves the patient bringing all medicines into the clinic for a provider to review. In addition, the clinician can assess patients' ability to read medication label directions, self-administer and manage medications in an organized manner. Currently, there is not a consensus or specific guideline on the management of polypharmacy or PIM in older adults with cancer. Interventions involving comprehensive medication management services in geriatric ambulatory and long term care facilities have shown a reduction in ineffective and unnecessary medications. ${ }^{66,80-82}$ Additionally, adherence of the patient to use their medication properly is a particular point of interest for nurses and allied health care professionals, ${ }^{83}$ however, there is an existing gap in the literature regarding effective/validated tools to measure medication adherence and optimal interventions to improve adherence in the setting polypharmacy.

\section{Geriatric Syndromes in General and the Older Adult with Cancer}

Older persons are susceptible to certain conditions that have been termed geriatric syndromes. These are health-related conditions that do not follow a specific diagnosis, are prevalent especially in frail, older persons, and can lead to poor outcomes including disability and altered QoL. ${ }^{84}$ There is no one definition of what constitutes a geriatric syndrome. The current SIOG GA guideline outlined them as: dementia, delirium, incontinence, osteoporosis, neglect or abuse, failure to thrive, falls, constipation, polypharmacy, pressure ulcers, and sarcopenia. ${ }^{5}$

\subsection{Advice for Nurses and Allied Health Care Professionals}

The Fulmer SPICES assessment tool has been used to uncover common syndromes and evaluates for evidence of sleep disorders, problems with eating or feeding, incontinence, confusion, evidence of falls, and skin breakdown. ${ }^{85}$ In 2007 Inouye, et al conducted a systematic review of geriatric syndromes and risk factors, they investigated five: pressure ulcers, incontinence, falls, functional decline, and delirium. ${ }^{84}$ The Hartford Institute of Nursing website (www.hartfordign.org) has multiple assessment tools for each syndrome identified. ${ }^{86}$ Because many of these syndromes are multi-factorial and not specifically related to a diagnosis they may be overlooked by the clinician attending to a specific diagnosis. The nurse or allied health care professional can serve as a key observer for geriatric syndromes and assess using one of the suggested tools or guideline. Positive screens will require further workup by specialists in these areas, for example, a patient experiencing incontinence can be referred to urology for interventions which may include bladder training or appropriate devices and exercises. A positive screen for poor sleep can lead to a discussion by the nurse of non-pharmacological methods to induce sleep.

\section{Geriatric Syndrome: Delirium and the Older Adult with Cancer}

Patients with cognitive impairments are at a higher risk for delirium, ${ }^{87}$ especially during and after cancer treatment and when the older patient is hospitalized. Delirium incidence has been reduced in medical and surgical wards with the implementation of a delirium prevention protocol. ${ }^{88,89}$ Although these studies were not in cancer populations the interventions involve meeting basic care needs, such as hydration, orientation, and mobility. These interventions could be initiated in an oncology setting.

\subsection{Advice for Nurses and Allied Health Care Professionals}

Delirium screening can be done using a screening tool such as the Confusion Assessment Method (CAM), ${ }^{90}$ Memorial Delirium Assessment Scale (MDAS), ${ }^{91}$ or the Delirium Rating Scale-Revised 98 (DRS-R-98), ${ }^{92}$ all of which have been validated in an oncology setting. ${ }^{93}$ 


\section{Geriatric Syndrome: Falls and the Older Adult with Cancer}

Falls are a common problem in the general older population and the older population with cancer. ${ }^{94}$ One third of older adults fall annually and up to half of these patients will experience recurrent falls. ${ }^{95,96}$ Falls represent a major cause of morbidity, mortality, and functional decline. ${ }^{95,97}$ The etiology of a fall is often multi-factorial due to a combination of physiological age-related changes, pathological elements and behavioral or environmental factors. ${ }^{98,99}$ Therefore, identification of strong fall predictors is essential in the planning of preventive measures. Recently, the history of a fall in the year before cancer treatment was identified as a main predictor of falls occurring after cancer treatment. ${ }^{94}$

\subsection{Advice for Nurses and Allied Health Care Professionals}

Preventive measures, in high fall risk patients according to identified fall predictors, can be tailored to an individual patient by considering those factors that contributed to the high fall risk. According to fall risk assessment and the implementation of preventive measures, several guidelines have been developed such as the American Geriatrics Society (AGS) 'Prevention of falls in older persons ${ }^{\prime 100}$ and the National Institute of Health and Care Excellence (NICE) guideline 'Falls: assessment and prevention of falls in older people'101 both are recommended.

\section{Quality of Life and the Older Adult with Cancer}

Quality of Life (QoL), although not formally part of the GA, is a patient-reported outcome which complements the clinician's evaluation of clinical progress and determination of clinical benefits. The importance of maximizing functional status and QoL throughout the course of disease and treatment in older cancer population is growing. ${ }^{102}$ For older patients with cancer, symptom burden and psychological distress caused by cancer diagnosis and treatment in conjunction with pre-existing comorbid condition and geriatric syndromes cause profound impact on QoL. While numerous factors including age, type of chemotherapy, cancer site, symptom severity, and burden of comorbidity have been shown to relate to QoL, the findings are mixed. ${ }^{103,104}$ Previous cross-sectional studies suggested an association between the symptom cluster, functional status, and QoL in older patients with cancer receiving cancer treatment. ${ }^{56,58}$

\subsection{Advice for Nurses and Allied Health Care Professionals}

Nurses and allied health care professionals can incorporate QoL assessment into patient care and be proactive in providing supportive care to older patients during their treatment trajectory. The European Organization for Research and Treatment of Cancer (EORTC) QLQ-ELD $14^{105}$ is a geriatric-oncology specific QoL instrument, which has been recently developed and validated to

Table 1 - Domains of geriatric assessment resources.

Geriatric assessment domain

\begin{tabular}{|c|c|}
\hline Demographic data, and social support & $\begin{array}{l}\text { Medical Outcomes Social Support Survey (MOS-SS) }{ }^{11} \\
\text { Modified Caregiver Strain Index (MCSI) }\end{array}$ \\
\hline Comorbidity & Charlson Comorbidity Index $(\mathrm{CCI})^{14}$ \\
\hline & Cumulative Illness Rating Scale for Geriatrics (CIRS-G) ${ }^{107}$ \\
\hline Functional status & $\begin{array}{l}\text { Lawton scale for instrumental activities of daily living (IADL) })^{30} \\
\text { Katz Index of Independence in Activities of Daily Living (ADL) }\end{array}$ \\
\hline Cognition & $\begin{array}{l}\text { Mini-COG }{ }^{36} \\
\text { Mini Mental State Examination (MMSE) }{ }^{37} \\
\text { Montreal Cognitive Assessment (MOCA) }\end{array}$ \\
\hline Depression & Geriatric Depression Scale (GDS) ${ }^{42}$ \\
\hline Nutrition & $\begin{array}{l}\text { Malnutrition Screening Tool (MSTC) })^{109} \\
\text { Mini Nutritional Assessment (MNA) } \\
\text { Patient-generated Subjective Global Assessment (PG-SGA) } \\
\text { by dietitian if screening is positive }\end{array}$ \\
\hline Fatigue & $\begin{array}{l}\text { Functional Assessment of Cancer Therapy: Fatigue (FACT-F) } \\
\text { EORTC QLQ C30 (Fatigue subscale) } \\
\text { Visual Analogue Scale }^{112}\end{array}$ \\
\hline Polypharmacy & $\begin{array}{l}\text { Brown bag method of medication reconciliation } \\
\text { Beers Criteria } \\
\text { Screening Tool of Older Person's Prescriptions (STOPP) } \\
\text { Medication Appropriateness Index (MAI) } \\
\text { M0,72 }\end{array}$ \\
\hline Geriatric syndromes & SPICES tool ${ }^{113}$ \\
\hline Delirium & $\begin{array}{l}\text { Confusion Assessment Method (CAM) })^{90} \\
\text { Memorial Delirium Assessment Scale (MDAS) } \\
\text { Delirium Rating Scale-Revised } 98 \text { (DRS-R-98) } \\
\text { Delirium Observation Screening Scale (DOS) })^{114}\end{array}$ \\
\hline Falls & $\begin{array}{l}\text { American Geriatrics Society guideline }{ }^{100} \\
\text { National Institute of Health and Care Excellence (NICE) guideline }{ }^{101}\end{array}$ \\
\hline Quality of life & EORTC-QLQ-ELD $14^{105}$ \\
\hline
\end{tabular}


specifically assess the QoL issues in the oncogeriatric setting. Improvement in QoL may involve an effective management of symptoms and psychological distress, and supportive care and treatment in patients' co-morbid condition and geriatric syndromes.

\section{Conclusion}

Nurses and allied health care professionals have a crucial role in the care of older persons with cancer through the CGA process: identification of patients who can benefit from GA; performance of the geriatric screening and GA; development of geriatric recommendations for interventions; implementation of these recommendations in a care plan; and provision of follow-up and adjustment of the care plan with repeated CGA. A well-established follow-up increases the effectiveness of the whole CGA-process.

The ability of nurses and allied health care professionals to perform this particular assessment not only requires specialized training and education beyond standard oncology knowledge but also requires awareness for difficulties in language/communication problems (e.g. immigrant population) and health literacy in the older population. Knowledge of the key domains to assess in an older person with cancer can improve care by recognizing potential problems and intervening early. Currently there is no evidence available to define which time point is the most relevant to start the CGA process. However, in oncology the CGA process is often integrated when a treatment decision needs to be made. Nurses and allied health care professionals need to be aware of this particular time point to increase the level of integration of CGA. Future research is needed to define the ideal time point for CGA in older adults with cancer. Additionally, a systematic review of each domain is warranted in the oncology setting to further evaluate the best evidence based practice.

This opinion paper revealed briefly specific background information on the different key domains and the possible measuring instruments which are summarized in Table 1. Furthermore, organizational aspects should be reorganized to allow nurses and allied health care professionals to integrate this particular assessment in daily oncology practice (e.g. time / place).

\section{Disclosures and Conflict of Interest Statement}

None declared.

\section{Author Contributions}

Concept and design: P. Burhenn, A. McCarthy, A. Begue, G. Nightingale, K. Cheng, and C. Kenis.

Analysis and interpretation of data: P. Burhenn, A. McCarthy, A. Begue, G. Nightingale, K. Cheng, and C. Kenis.

Manuscript writing and approval: P. Burhenn, A. McCarthy, A. Begue, G. Nightingale, K. Cheng, and C. Kenis.

\section{R E F E R E N C E S}

1. World Health Organization. Cancer Fact Sheet Number 297 2014 [updated November 201401/09/2015]. Available from: http://www.who.int/mediacentre/factsheets/fs297/en/.

2. IOM. Retooling for an aging America: building the health care workforce. Institute of Medicine Medicine Io; 2008.

3. Rubenstein LZ, Stuck AE, Siu AL, Wieland D. Impacts of geriatric evaluation and management programs on defined outcomes: overview of the evidence. J Am Geriatr Soc 1991;39(9 Pt 2):8S-16S discussion 7S-8S.

4. Stuck AE, Siu AL, Wieland GD, Adams J, Rubenstein LZ. Comprehensive geriatric assessment - - a metaanalysis of controlled trials. Lancet 1993;342(8878):1032-1036.

5. Wildiers H, Heeren P, Puts M, Topinkova E, Janssen-Heijnen ML, Extermann M, et al. International society of geriatric oncology consensus on geriatric assessment in older patients with cancer. J Clin Oncol 2014;32(24):2595-2603.

6. Extermann M, Aapro M, Bernabei RB, Cohen HJ, Droz JP, Lichtman S, et al. Use of comprehensive geriatric assessment in older cancer patients: recommendations from the task force on CGA of the International Society of Geriatric Oncology (SIOG). Crit Rev Oncol Hematol 2005;55(3):241-252.

7. Boggatz T. Quality of life in old age - a concept analysis. Int J Older People Nurs 2015.

8. Heap J, Lennartsson C, Thorslund M. Coexisting disadvantages across the adult age span: a comparison of older and younger age groups in the Swedish welfare state. Int J Soc Welf 2013;22(2):130-140.

9. Hurria A, Lachs MS, Cohen H, Muss H, Kornblith AB. Geriatric assessment for oncologists: rationale and future directions. Crit Rev Oncol Haematol 2006;59:211-217.

10. National Comprehensive Cancer Network (NCCN). Senior Adult Oncology Version 2.2013: NCCN 2013 [cited 2012 1st May]. Available from: http://www.nccn.org/professionals/ physician-gls/PDF/senior.pdf.

11. Sherbourne CD, Stewart AL. The MOS social support survey. Soc Sci Med 1991;32(6):705-714.

12. Extermann M. Measuring comorbidity in older cancer patients. Euro J Cancer (Oxford, England: 1990) 2000;36(4): 453-471.

13. Geraci JM, Escalante CP, Freeman JL, Goodwin JS. Comorbid disease and cancer: the need for more relevant conceptual models in health services research. J Clin Oncol Off J Am Soc Clin Oncol 2005;23(30):7399-7404.

14. Charlson ME, Pompei P, Ales KL, MacKenzie CR. A new method of classifying prognostic comorbidity in longitudinal studies: development and validation. J Chronic Dis 1987;40(5): 373-383.

15. Linn BS, Linn MW, Gurel L. Cumulative illness rating scale. J Am Geriatr Soc 1968;16(5):622-626.

16. Wildiers $\mathrm{H}$, Kenis C. Comprehensive geriatric assessment (CGA) in older oncological patients: why and how? J Geriatr Oncol 2012;3(2):174-176.

17. Sogaard M, Thomsen RW, Bossen KS, Sorensen HT, Norgaard M. The impact of comorbidity on cancer survival: a review. Clin Epidemiol 2013;5(Suppl 1):3-29.

18. Repetto L, Fratino L, Audisio RA, Venturino A, Gianni W, Vercelli M, et al. Comprehensive geriatric assessment adds information to Eastern Cooperative Oncology Group performance status in elderly cancer patients: an Italian Group for Geriatric Oncology Study. J Clin Oncol Off J Am Soc Clin Oncol 2002;20(2):494-502.

19. Wedding U, Rohrig B, Klippstein A, Pientka L, Hoffken K. Age, severe comorbidity and functional impairment independently contribute to poor survival in cancer patients. J Cancer Res Clin Oncol 2007;133(12):945-950. 
20. Jordhoy MS, Fayers P, Loge JH, Saltnes T, Ahlner-Elmqvist M, Kaasa S. Quality of life in advanced cancer patients: the impact of sociodemographic and medical characteristics. $\mathrm{Br} J$ Cancer 2001;85(10):1478-1485.

21. Hoogerduijn JG, Schuurmans MJ, Korevaar JC, Buurman BM, de Rooij SE. Identification of older hospitalised patients at risk for functional decline, a study to compare the predictive values of three screening instruments. J Clin Nurs 2010;19(9-10):1219-1225.

22. Covinsky KE, Justice AC, Rosenthal GE, Palmer RM, Landefeld CS. Measuring prognosis and case mix in hospitalized elders. The importance of functional status. J Gen Intern Med 1997;12(4):203-208.

23. Fortinsky RH, Covinsky KE, Palmer RM, Landefeld CS. Effects of functional status changes before and during hospitalization on nursing home admission of older adults. $J$ Gerontol A Biol Sci Med Sci 1999;54(10):M521-M526.

24. Rudberg MA, Sager MA, Zhang J. Risk factors for nursing home use after hospitalization for medical illness. J Gerontol A Biol Sci Med Sci 1996;51(5):M189-M194.

25. McCusker J, Kakuma R, Abrahamowicz M. Predictors of functional decline in hospitalized elderly patients: a systematic review. J Gerontol A Biol Sci Med Sci 2002;57(9):M569-M577.

26. Versteeg KS, Konings IR, Lagaay AM, van de Loosdrecht AA, Verheul HM. Prediction of treatment-related toxicity and outcome with geriatric assessment in elderly patients with solid malignancies treated with chemotherapy: a systematic review. Ann Oncol 2014;25(10):1914-1918.

27. Yates JW, Chalmer B, McKegney FP. Evaluation of patients with advanced cancer using the Karnofsky performance status. Cancer 1980;45(8):2220-2224.

28. Oken MM, Creech RH, Tormey DC, Horton J, Davis TE, Mcfadden ET, et al. Toxicity and response criteria of the Eastern-Cooperative-Oncology-Group. Am J Clin Oncol Cancer Clin Trials 1982;5(6):649-655.

29. Katz S, Ford AB, Moskowitz RW, Jackson BA, Jaffe MW. Studies of illness in the aged. The index of ADL: a standardized measure of biological and psychosocial function. JAMA 1963;185:914-919.

30. Lawton MP, Brody EM. Assessment of older people: self-maintaining and instrumental activities of daily living. Gerontologist 1969;9(3):179-186.

31. Sattar S, Alibhai SM, Wildiers H, Puts MT. How to implement a geriatric assessment in your clinical practice. Oncologist 2014;19(10):1056-1068.

32. Chester JG, Grande LJ, Milberg WP, McGlinchey RE, Lipsitz LA, Rudolph JL. Cognitive screening in community-dwelling elders: performance on the clock-in-the-box. Am J Med 2011;124(7):662-669.

33. Huang CQ Wang ZR, Li YH, Xie YZ, Liu QX. Cognitive function and risk for depression in old age: a meta-analysis of published literature. Int Psychogeriatr 2011;23(4):516-525.

34. McKoy JM, Burhenn PS, Browner IS, Loeser KL, Tulas KM, Oden MR, et al. Assessing cognitive function and capacity in older adults with cancer. J Natl Compr Cancer Netw. JNCCN 2014;12(1):138-144.

35. Inouye SK, Westendorp RG, Saczynski JS. Delirium in elderly people. Lancet 2014;383(9920):911-922.

36. Borson S, Scanlan J, Brush M, Vitaliano P, Dokmak A. The mini-cog: a cognitive 'vital signs' measure for dementia screening in multi-lingual elderly. Int J Geriatr Psychiatry 2000;15(11):1021-1027.

37. Folstein MF, Folstein SE, McHugh PR. "Mini-mental state". A practical method for grading the cognitive state of patients for the clinician. J Psychiatr Res 1975;12(3):189-198.

38. Network National Comprehensive Cancer. NCCN Clinical Practice Guidelines in Oncology: Older Adult Oncology 2015 [cited; 2015 June 30. Available from:http://www.nccn.org/ professionals/physician_gls/pdf/senior.pdf.
39. Hybels CF, Blazer DG. Epidemiology of late-life mental disorders. Clin Geriatr Med 2003;19(4):663-696 v.

40. Li M, Fitzgerald P, Rodin G. Evidence-based treatment of depression in patients with cancer. J Clin Oncol 2012;30(11): 1187-1196.

41. Kai-hoi Sze F, Wong E, Lo R, Woo J. Do pain and disability differ in depressed cancer patients? Palliat Med 2000;14(1):11-17.

42. Yesavage JA, Brink TL, Rose TL, Lum O, Huang V, Adey M, et al. Development and validation of a geriatric depression screening scale: a preliminary report. J Psychiatr Res 1982;17(1):37-49.

43. Massa E, Madeddu C, Astara G, Pisano M, Spiga C, Tanca FM. An attempt to correlate a "Multidimensional Geriatric Assessment" (MGA), treatment assignment and clinical outcome in elderly cancer patients: Results of a phase II open study. Crit Rev Oncol Haematol 2008;66:75-83.

44. Cohen G, Mary Jose S, Ahronheim JC. BODY mass index: pitfalls in elderly people. J Am Geriatr Soc 2009;57(1):170-172.

45. Kimyagarov S, Klid R, Levenkrohn S, Fleissig Y, Kopel B, Arad $\mathrm{M}$, et al. Body mass index (BMI), body composition and mortality of nursing home elderly residents. Arch Gerontol Geriatr 2010;51(2):227-230.

46. Isenring E, Cross G, Kellett E, Koczwara B, Daniels L. Nutritional status and information needs of medical oncology patients receiving treatment at an Australian public hospital. Nutr Cancer 2010;62(2):220-228.

47. Kim JY, Wie GA, Cho YA, Kim SY, Kim SM, Son KH, et al. Development and validation of a nutrition screening tool for hospitalized cancer patients. Clin Nutr (Edinburgh, Scotland) 2011;30(6):724-729.

48. Vellas B, Guigoz Y, Garry PJ, Nourhashemi F, Bennahum D, Lauque $\mathrm{S}$, et al. The mini nutritional assessment (MNA) and its use in grading the nutritional state of elderly patients. Nutrition 1999;15(2):116-122.

49. Sullivan DH, Roberson PK, Bopp MM. Hypoalbuminemia 3 months after hospital discharge: significance for long-term survival. J Am Geriatr Soc 2005;53(7):1222-1226.

50. Bjorkman MP, Sorva AJ, Risteli J, Tilvis RS. Low parathyroid hormone levels in bedridden geriatric patients with vitamin D deficiency. J Am Geriatr Soc 2009;57(6):1045-1050.

51. Knopman DS, DeKosky ST, Cummings JL, Chui H, Corey-Bloom J, Relkin N, et al. Practice parameter: diagnosis of dementia (an evidence-based review). Report of the Quality Standards Subcommittee of the American Academy of Neurology. Neurology 2001;56(9):1143-1153.

52. Giacalone A, Quitadamo D, Zanet E, Berretta M, Spina M, Tirelli U. Cancer-related fatigue in the elderly. Support Care Cancer 2013;21(10):2899-2911.

53. Piper BF, Cella D. Cancer-related fatigue: definitions and clinical subtypes. J Natl Compr Cancer Netw JNCCN 2010;8(8): 958-966.

54. Berger AM, Gerber LH, Mayer DK. Cancer-related fatigue: implications for breast cancer survivors. Cancer 2012;118(8 Suppl):2261-2269.

55. Miller AH, Ancoli-Israel S, Bower JE, Capuron L, Irwin MR. Neuroendocrine-immune mechanisms of behavioral comorbidities in patients with cancer. J Clin Oncol Off J Am Soc Clin Oncol 2008;26(6):971-982.

56. Cheng KK, Lee DT. Effects of pain, fatigue, insomnia, and mood disturbance on functional status and quality of life of elderly patients with cancer. Crit Rev Oncol Hematol 2011;78(2): 127-137.

57. Dodd MJ, Miaskowski C, Paul SM. Symptom clusters and their effect on the functional status of patients with cancer. Oncol Nurs Forum 2001;28(3):465-470.

58. Kozachik SL, Bandeen-Roche K. Predictors of patterns of pain, fatigue, and insomnia during the first year after a cancer diagnosis in the elderly. Cancer Nurs 2008;31(5): 334-344. 
59. Functional Assessment of Chronic Illness Therapy (FACIT). functional assessment of chronic illness therapy-fatigue [cited. 2015 July 1 Available from:http://www.facit.org/ FACITOrg/Questionnaires.

60. EORTC Quality of Life Department. EORTC QLQ-C30 [cited. 2015 July 1 Available from:http://groups.eortc.be/qol/ eortc-qlq-c30.

61. Mock V, Atkinson A, Barsevick AM, Berger AM, Cimprich B, Eisenberger MA, et al. Cancer-related fatigue. Clinical practice guidelines in oncology. J Natl Compr Cancer Netw JNCCN 2007;5(10):1054-1078.

62. Goedendorp MM, Gielissen MF, Verhagen CA, Bleijenberg G. Psychosocial interventions for reducing fatigue during cancer treatment in adults. Cochrane Database Syst Rev 2009(1)Cd006953.

63. Kangas M, Bovbjerg DH, Montgomery GH. Cancer-related fatigue: a systematic and meta-analytic review of non-pharmacological therapies for cancer patients. Psychol Bull 2008;134(5):700-741.

64. Stewart RB. Polypharmacy in the elderly: a fait accompli? DICP 1990;24(3):321-323.

65. Montamat SC, Cusack B. Overcoming problems with polypharmacy and drug misuse in the elderly. Clin Geriatr Med 1992;8(1):143-158.

66. Hajjar ER, Cafiero AC, Hanlon JT. Polypharmacy in elderly patients. Am J Geriatr Pharmacother 2007;5(4):345-351.

67. American Geriatrics Society Beers Criteria Update Expert P. American Geriatrics Society updated Beers Criteria for potentially inappropriate medication use in older adults. $J$ Am Geriatr Soc 2012;60(4):616-631.

68. Gallagher P, O'Mahony D. STOPP (Screening Tool of Older Persons' potentially inappropriate Prescriptions): application to acutely ill elderly patients and comparison with Beers' criteria. Age Ageing 2008;37(6):673-679.

69. Hamilton H, Gallagher P, Ryan C, Byrne S, O'Mahony D. Potentially inappropriate medications defined by STOPP criteria and the risk of adverse drug events in older hospitalized patients. Arch Intern Med 2011;171(11):1013-1019.

70. Hanlon JT, Schmader KE, Samsa GP, Weinberger M, Uttech $\mathrm{KM}$, Lewis IK, et al. A method for assessing drug therapy appropriateness. J Clin Epidemiol 1992;45(10):1045-1051.

71. O'Mahony D, O'Sullivan D, Byrne S, O'Connor MN, Ryan C, Gallagher P. STOPP/START criteria for potentially inappropriate prescribing in older people: version 2. Age Ageing 2015;44(2):213-218.

72. Samsa GP, Hanlon JT, Schmader KE, Weinberger M, Clipp EC, Uttech $\mathrm{KM}$, et al. A summated score for the medication appropriateness index: development and assessment of clinimetric properties including content validity. J Clin Epidemiol 1994;47(8):891-896.

73. O'mahony D, Gallagher P, Ryan C, Byrne S, Hamilton H, Barry P, et al. STOPP \& START criteria: a new approach to detecting potentially inappropriate prescribing in old age. Eur Geriatr Med 2010;1(1):45-51.

74. American Geriatrics Society 2015 Updated Beers Criteria for Potentially Inappropriate Medication Use in Older Adults. J Am Geriatr Soc 2015;63(11):2227-2246.

75. Prithviraj GK, Koroukian S, Margevicius S, Berger NA, Bagai R, Owusu C. Patient characteristics associated with Polypharmacy and Inappropriate prescribing of medications among older adults with cancer. J Geriatr Oncol 2012;3(3): 228-237.

76. Maggiore RJ, Feng T, Dale W, Gross CP, Tew WP, Mohile SG, et al. Measures of polypharmacy and chemotherapy toxicity in older adults with cancer. J Clin Oncol 2013;31:15.

77. Nightingale G, Hajjar E, Swartz K, Andrel-Sendecki J, Chapman A. Evaluation of a pharmacist-led medication assessment used to identify prevalence of and associations with polypharmacy and potentially inappropriate medication use among ambulatory senior adults with cancer. J Clin Oncol Off J Am Soc Clin Oncol 2015;33(13): 1453-1459.

78. Lichtman SM, Boparai MK. Geriatric medication management: evaluation of pharmacist interventions and potentially inappropriate medication (PIM) use in older ( $\geq 65$ years) cancer patients. J Clin Oncol Off J Am Soc Clin Oncol 2009;27(15s) abstr 9507.

79. Maggiore RJ, Gross CP, Hardt M, Tew WP, Mohile SG, Klepin $\mathrm{HD}$, et al. Polypharmacy, potentially inappropriate medications, and chemotherapy-related adverse events among older adults with cancer. J Clin Oncol Off J Am Soc Clin Oncol 2011;29(15s) abstr e19501.

80. Marcum ZA, Handler SM, Wright R, Hanlon JT. Interventions to improve suboptimal prescribing in nursing homes: a narrative review. Am J Geriatr Pharmacother 2010;8(3):183-200.

81. Steinman MA, Hanlon JT. Managing medications in clinically complex elders: "there's got to be a happy medium". JAMA, J Am Med Assoc 2010;304(14):1592-1601.

82. Patterson SM, Hughes C, Kerse N, Cardwell CR, Bradley MC. Interventions to improve the appropriate use of polypharmacy for older people. Cochrane Database Syst Rev 2012;5.

83. Winkeljohn D. Adherence to oral cancer therapies: nursing interventions. Clin J Oncol Nurs 2010;14(4):461-466.

84. Inouye SK, Studenski S, Tinetti ME, Kuchel GA. Geriatric syndromes: clinical, research, and policy implications of a core geriatric concept. J Am Geriatr Soc 2007;55(5):780-791.

85. Fulmer TT. The geriatric nurse specialist role: a new model. Nurs Manage 1991;22(3):91-93.

86. Hartford Institute for Geriatric Nursing. Assessment Tools-Try This 2015 [February, 6, 2015]. Available from: http://www.hartfordign.org/practice/try_this/.

87. NICE. Delirium. Diagnosis prevention and management. London: National Institute for Health Clinical Excellence (NICE); 2010. Available from: http://www.nice.org.uk/ guidance/CG103/chapter/1-Guidance.

88. Inouye SK, Bogardus Jr ST, Williams CS, Leo-Summers L, Agostini JV. The role of adherence on the effectiveness of nonpharmacologic interventions: evidence from the delirium prevention trial. Arch Intern Med 2003;163(8):958-964.

89. Marcantonio ER, Flacker JM, Wright RJ, Resnick NM. Reducing delirium after hip fracture: a randomized trial. J Am Geriatr Soc 2001;49(5):516-522.

90. Inouye SK, van Dyck CH, Alessi CA, Balkin S, Siegal AP, Horwitz RI. Clarifying confusion: the confusion assessment method. A new method for detection of delirium. Ann Intern Med 1990;113(12):941-948.

91. Breitbart W, Rosenfeld B, Roth A, Smith MJ, Cohen K, Passik S The Memorial Delirium Assessment Scale. J Pain Symptom Manage 1997;13(3):128-137.

92. Trzepacz PT, Mittal D, Torres R, Kanary K, Norton J, Jimerson N. Validation of the Delinium Rating Scale-revised-98: comparison with the delirium rating scale and the cognitive test for delinium. J Neuropsychiatry Clin Neurosci 2001;13(2):229-242.

93. Breitbart W, Alici Y. Evidence-based treatment of delirium in patients with cancer. J Clin Oncol Off J Am Soc Clin Oncol 2012;30(11):1206-1214.

94. Vande Walle N, Kenis C, Heeren P, Van Puyvelde K, Decoster L, Beyer I, et al. Fall predictors in older cancer patients: a multicenter prospective study. BMC Geriatr 2014;14:135

95. Dionyssiotis Y. Analyzing the problem of falls among older people. Int J Gen Med 2012;5:805-813.

96. O'Halloran AM, Penard N, Galli A, Fan CW, Robertson IH, Kenny RA. Falls and falls efficacy: the role of sustained attention in older adults. BMC Geriatr 2011;11:85.

97. Rubenstein LZ. Falls in older people: epidemiology, risk factors and strategies for prevention. Age and ageing 2006;35(Suppl 2):ii37-ii41. 
98. Hanley A, Silke C, Murphy J. Community-based health efforts for the prevention of falls in the elderly. Clin Interv Aging 2011;6:19-25.

99. Ungar A, Rafanelli M, Iacomelli I, Brunetti MA, Ceccofiglio A, Tesi F, et al. Fall prevention in the elderly. Clin Cases Miner Bone Metabol 2013;10(2):91-95.

100. Fetveit A. Late-life insomnia: a review. Geriatr Gerontol Int 2009;9(3):220-234.

101. Friedman L, Zeitzer JM, Kushida C, Zhdanova I, Noda A, Lee $\mathrm{T}$, et al. Scheduled bright light for treatment of insomnia in older adults. J Am Geriatr Soc 2009;57(3):441-452.

102. Cohen HJ. Cancer and the functional status of the elderly. Cancer 1997;80(10):1883-1886.

103. Browall M, Ostlund U, Henoch I, Wengstrom Y. The course of Health Related Quality of Life in postmenopausal women with breast cancer from breast surgery and up to five years post-treatment. Breast 2013;22(5):952-957.

104. Delforge M, Dhawan R, Robinson Jr D, Meunier J, Regnault A, Esseltine DL, et al. Health-related quality of life in elderly, newly diagnosed multiple myeloma patients treated with VMP vs. MP: results from the VISTA trial. Eur J Haematol 2012;89(1):16-27.

105. EORTC Quality of Life Department. Elderly Cancer Patients (QLQ - ELD14) [cited. July 12015 Available from: http:// groups.eortc.be/qol/elderly-cancer-patients-qlq-eld14.

106. Thornton M, Travis SS. Analysis of the reliability of the modified caregiver strain index. J Gerontol B Psychol Sci Soc Sci 2003;58(2):S127-S132.
107. Miller MD, Paradis CF, Houck PR, Mazumdar S, Stack JA, Rifai $\mathrm{AH}$, et al. Rating chronic medical illness burden in geropsychiatric practice and research: application of the Cumulative Illness Rating Scale. Psychiatry Res 1992;41(3): 237-248.

108. Smith T, Gildeh N, Holmes C. The Montreal Cognitive Assessment: validity and utility in a memory clinic setting. Can J Psychiatr Rev Can Psychiatr 2007;52(5):329-332.

109. Isenring E, Cross G, Daniels L, Kellett E, Koczwara B. Validity of the malnutrition screening tool as an effective predictor of nutritional risk in oncology outpatients receiving chemotherapy. Support Care Cancer 2006;14(11):1152-1156.

110. Vellas B, Villars H, Abellan G, Soto ME, Rolland Y, Guigoz Y, et al. Overview of the MNA-its history and challenges. J Nutr Health Aging 2006;10(6):456-463 discussion 63-5.

111. Bauer J, Capra S, Ferguson M. Use of the scored Patient-Generated Subjective Global Assessment (PG-SGA) as a nutrition assessment tool in patients with cancer. Eur J Clin Nutr 2002;56(8):779-785.

112. Mock V. Evidence-based treatment for cancer-related fatigue. J Natl Cancer Inst Monogr 2004;32:112-118.

113. Fulmer T. How to try this: Fulmer SPICES. Am J Nurs 2007;107(10):40-48 quiz 8-9.

114. Schuurmans MJ, Duursma SA, Shortridge-Baggett LM. Early recognition of delirium: review of the literature. J Clin Nurs 2001;10(6):721-729. 